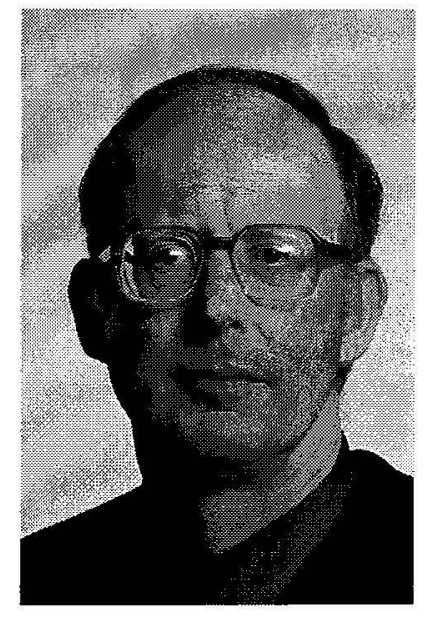

\title{
PRACTICAL USES OF THE \\ HUMAN CAPABILITY \\ FRAMEWORK - AN \\ OUTSIDERS'S VIEW OF A \\ CONCEPT GUIDING PUBLIC \\ POLICY AND RESEARCH
}

\author{
Rupert Tipples \\ Farm and Horticultural Management \\ Groups \\ Applied Management and Computing \\ Division \\ Lincoln University
}

\begin{abstract}
The Human Capability Framework (HCF) was presented at LEW 9 as a really exciting concept that had proved very useful in Massey University's Labour Market Dynamics Research Programme. It had come from the Department of Labour. Personal amazement at the apparent change of direction in the Department's thinking this represented was succeeded by the realisation of its immediate usefulness for a research funding application then in process.

This paper explores the author's perceptions of the original model and its origins. Then the outcomes that have flowed from the use of the model in the succeeding two years is considered. After an initial explanation of the HCF, there is an analysis of its use as a policy tool at national and regional levels. Its use in various research projects is described as well. The paper concludes with a consideration of the academic acceptability of the concept and some questions for further research.
\end{abstract}

At LEW 9 my perception of the Department of Labour, and particularly its Labour Market Policy Group, was shattered by the presentation of Bartley, Dupuis and Bruin (Bartley, Dupuius and de Bruin, 2001, 148-155). I had seen that Group as dominated by neo-liberal labour market econometricians with no appreciation of the real world problems of employment, particularly in small business. That was the view of an outsider. Of English origin and based at Lincoln, my contacts with the Department of Labour were largely confined to the biennial Labour, Employment and Work conferences, which I had attended since the 1980s. I had formed those views from the content of their presentations and papers, and from the conflicts and debates surrounding the passage of the Employment Contracts Act 1991. Bartley et al.'s presentation of the Human Capability Framework as a useful concept that covered not just economic issues in the labour market but also social factors of which I was more familiar was a revelation. They described it as "...on the one hand both complex and sophisticated and on the other disarmingly simple" (Bartley et al., 2001, 149).

Since LEW 9 in 2000 there have been a lot of developments in the use of the Human Capability Framework (HCF). The aims of this paper are first to further promote what I, and others, have clearly found to be a valuable idea. Secondly, it is to review the development of the concept, and then thirdly to consider its uses in public policy and research. Finally, the paper seeks to explore future research needed to maximise the possibilities that the framework provides.

\section{Background}

As indicated above, the presentation of Bartley et al. on "Regional Labour Market Dynamics and Economic Participation" was the first indication I, and no doubt some others, had of the Human Capability Framework (HCF). It seemed as though the Labour Market Policy Group and the Department 'had seen the light', in that they had abandoned just an econometric approach to employment problems, and were beginning to consider social and other factors as well.

As an outsider, this account may be incomplete or inaccurate, and one of the purposes of this particular presentation is to 'flush out' the real story! I have tried to do this from the literature and my limited contacts, but have never been satisfied that I have managed to get the full story. My understanding of the ideas underpinning the framework are still evolving and I am finding the development of these ideas and how they have been increasingly influencing public policy quite fascinating. 
Understanding the evolution of these ideas is fundamental to explaining the evolution of Government Policy since 1999.

In the year 1998-1999 the Department of Labour underwent major changes. It lost the New Zealand Employment Service, and the Local Employment Coordination function which were transferred to Work and Income New Zealand. These changes resulted in a rethinking of the Department's purpose, which became:

"We link social and economic issues to enable people to develop and utilise their potential for the advantage of themselves and New Zealand." (DoL, 1998, 3)

The social was coming to the fore after the ascendancy of the 'new public management' and 'economic rationalism' of the 1980s and early 1990s.

The most likely source of the Human Capability Framework seems to have been a request from the Chief Executive of the Department of Labour, John Chetwin. He requested his staff "to begin a project to establish a framework for developing policies relating to the development of New Zealand's human capability" (DoL, $1999 \mathrm{~b}, 3)$. This began in late 1998 and resulted in a full paper published just before the 1999 General Election (DoL, 1999c). Writing subsequently Chetwin describes it as a key dimension of the Department's strategic thinking:

"It is a framework that provides a way of thinking about the linkages between social and economic issues and is directly connected with the Department's purpose... The Department is now using the HCF as a context for all its policy advice and to facilitate connections between each of its Services at an operational level...The overall objective - the effective development of New Zealand's human capability." (DoL, 2000b, 3)

What is human capability?

"Human capability is the ability of people to do things - both the capacity and the opportunities to do things" (Dol, 1999c, 4).

As such it is a much more active and encompassing concept than 'human capital'.

Bartley et al. (2001) have suggested that one of the factors involved in the development of the HCF was the influence of OECD on policy development. The HCF provided an "....integrated view of key economic and social objectives, and an understanding of the role of the labour market in achieving them" (p. 149). It was a counter to the dominant human capital paradigm advanced by the OECD for considering issues of employment and employability. Bartley et al. $(2001,150)$ express it thus:

"One concern about the human capital approach is its assumptions of individuals as rational maximisers of individual utility: that is, that people make decisions about maximising their own opportunities and develop their potential to maximise future opportunities based upon rational considerations of self-interest and unlimited choice. The HCF allows for a more holistic - and realistic - view of individuals as being embedded in a variety of social relations that affect their choices and aspirations in a way that human capital simply does not".

The HCF has already been amply described but it is necessary to outline it for the benefit of those unfamiliar with it. It is portrayed in Figure 1.

Figure 1: The Human Capability Framework

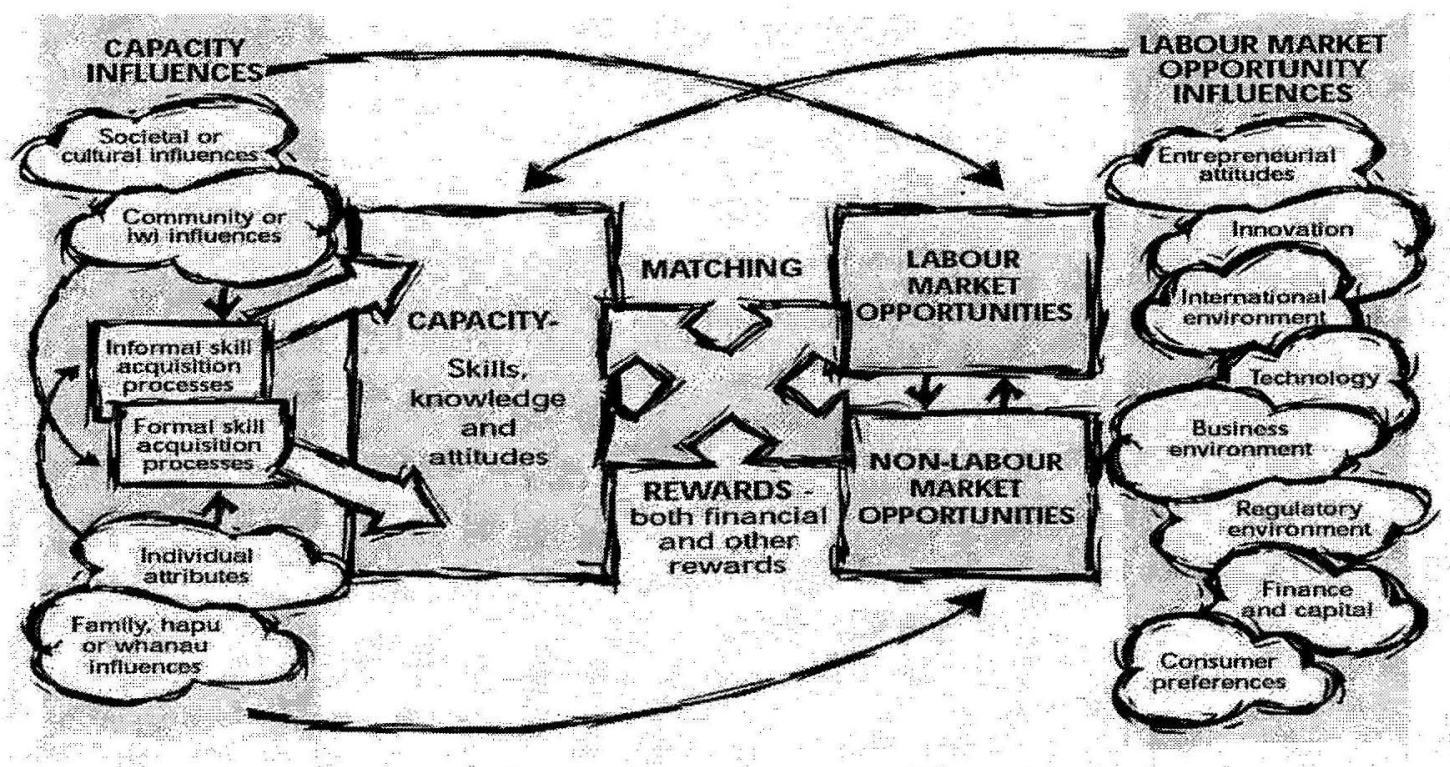




\section{The Human Capability Framework}

The Human Capability Framework (HCF) has been presented as an holistic way to approach labour markets. It has three main components, capacity, opportunities, and matching, which provide a basis from which individuals may be seen as participating in a variety of social relations that affect their choices and aspirations. "Capacity" refers to the skills, knowledge and attitudes people possess and how in using these skills, they can take advantage of the labour market and other opportunities available to them. The HCF also illustrates the importance of the networks that people are involved in as an influence on their capacity in the labour market. "Opportunities" are the alternatives available to people to use their capacity (i.e., skills, knowledge and attitudes) as a way in which they gain financial or personal reward. "Matching" links people's capacity and labour market opportunity. Matching is a distinct set of processes that considers the influences on both these elements. Acknowledging each element as a process in its own right enables us to discover the breadth of each concept before analysing the impact each has on the other. As the link between capacity and opportunity, matching is affected by the quality of information that flows between the two. Matching allows us to explore what it is that increases capacity for the particular job skill required and the conditions under which this capacity meaningfully increases. The HCF is a valuable tool when considering the way in which the labour market operates. It is based on the premise that a wide variety of influences affect human capability, both socially and economically. The matching process allows us to see each 'cloud' in the diagram as a contributing factor to success in the matching process which may otherwise be overlooked. The adoption of this concept ensures that subtle factors which might influence the effectiveness of "capacity formation, opportunity creation....and the matching process" are recognised (DoL 1999c, 20-24).

During 2000/01 a new mission statement for the Department of Labour was developed to fit this purpose: Wired for work and wellbeing. Wired reflected the connectedness of developing policy between services provided, communities, businesses, government and internationally, and incorporating social and economic issues. Work reflects the primary role of 'labour' and the responsibilities for “...building capacity, opportunities and matching in the labour market that promote fair, safe, satisfying work and balanced immigration". Wellbeing is another term featuring in OECD documentation (e.g., OECD, 2001) and covers the outcomes of Government policy resulting from the promotion of opportunities for social and economic development, and "...thriving, wellsettled, inclusive communities”. (DoL, 2001b, 7)

\section{Policy uses of the HCF}

The first significant appearance of the Human Capability Framework as already reported by Bartley et al. (2001) was in the Ministerial briefing papers after the 1999 General Election (DoL, 1999d). Then it featured significantly in the Department's last Corporate Plan 1999-2000 and in the succeeding Strategic Directions documents of 2000-2001, 2001-2002 and 2002-2003. It is also a feature of Department of Labour Annual Reports to the House of Representatives from 1999. Further, it was a central feature of Workforce 2010 - a document to inform public debate on the future of the labour market in New Zealand published by the Department in 2001. In Strategic Directions 2000-2001 one form of the regular use of the framework is exhibited for each service area of the Department. To illustrate this use, Figure 2 applies the matching model to the Employment Relations field.

Figure 2: Applying the HCF to Employment Relations
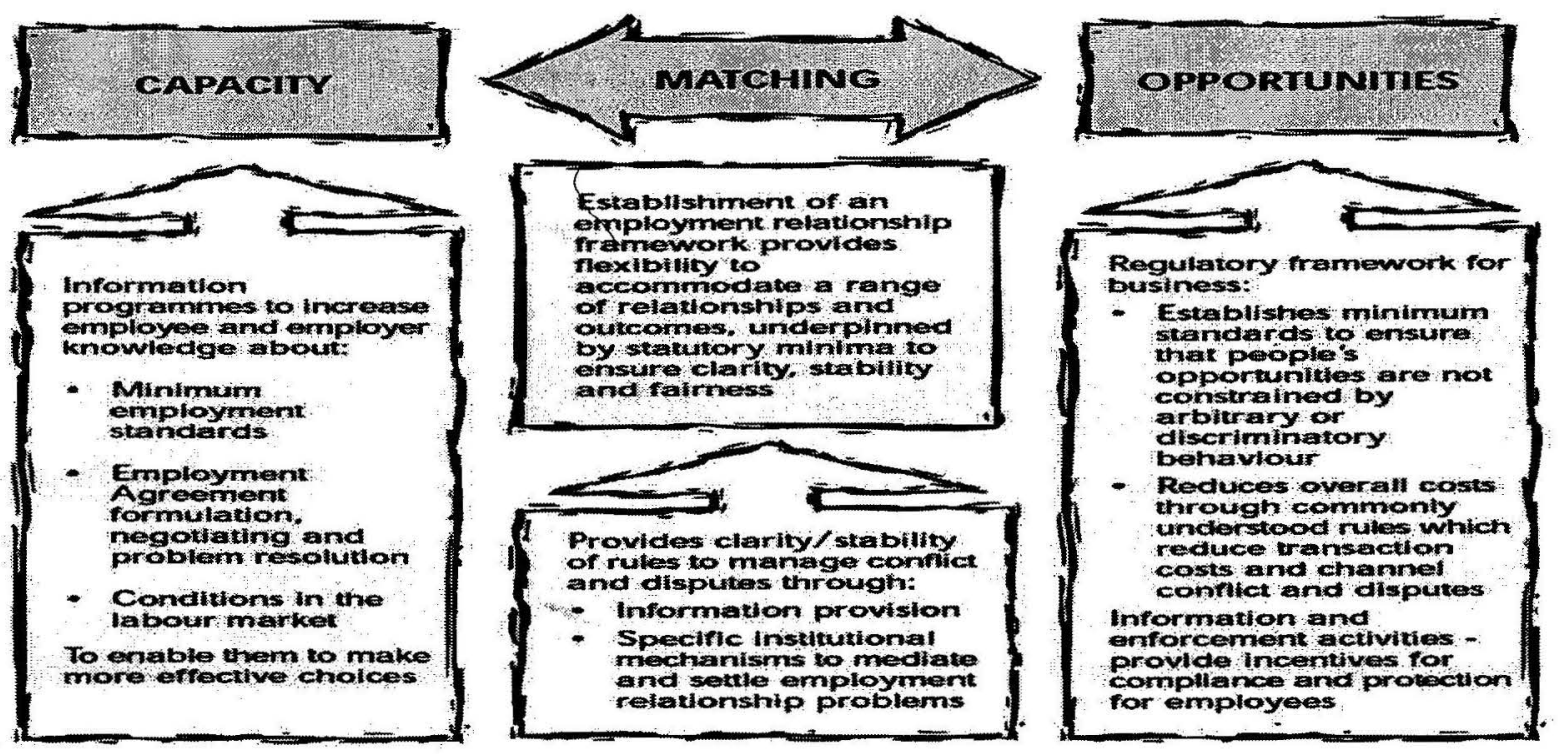
Moreover, the same basic framework can be applied to matters of regional policy and not just that of central government. The Canterbury Development Corporation has applied the framework and the other features of the Workplace 2010 document to the Canterbury Region. The outcome of this application can be seen in Figure 3. Figure 3 looks at Capacity and Opportunities as the Supply and Demand sides of the labour market and maps out the key issues facing the Canterbury Development Corporation as a key service and delivery body involved in the matching processes in Canterbury. It provides another view of the framework with different headings under the Capacity and Opportunity headings resulting from an analysis of the risks and opportunities likely to appear in the Canterbury labour market over the next three years. Each of these is then considered as it affects each age subset of the supply side of the framework: Under 15, Youth 15-24, Mainstream 25-49, Third Age $50-64$, and those aged 65 or more (Canterbury Development Corporation, 2002).

Figure 3: Key labour issues facing the Canterbury Development Council to 2010

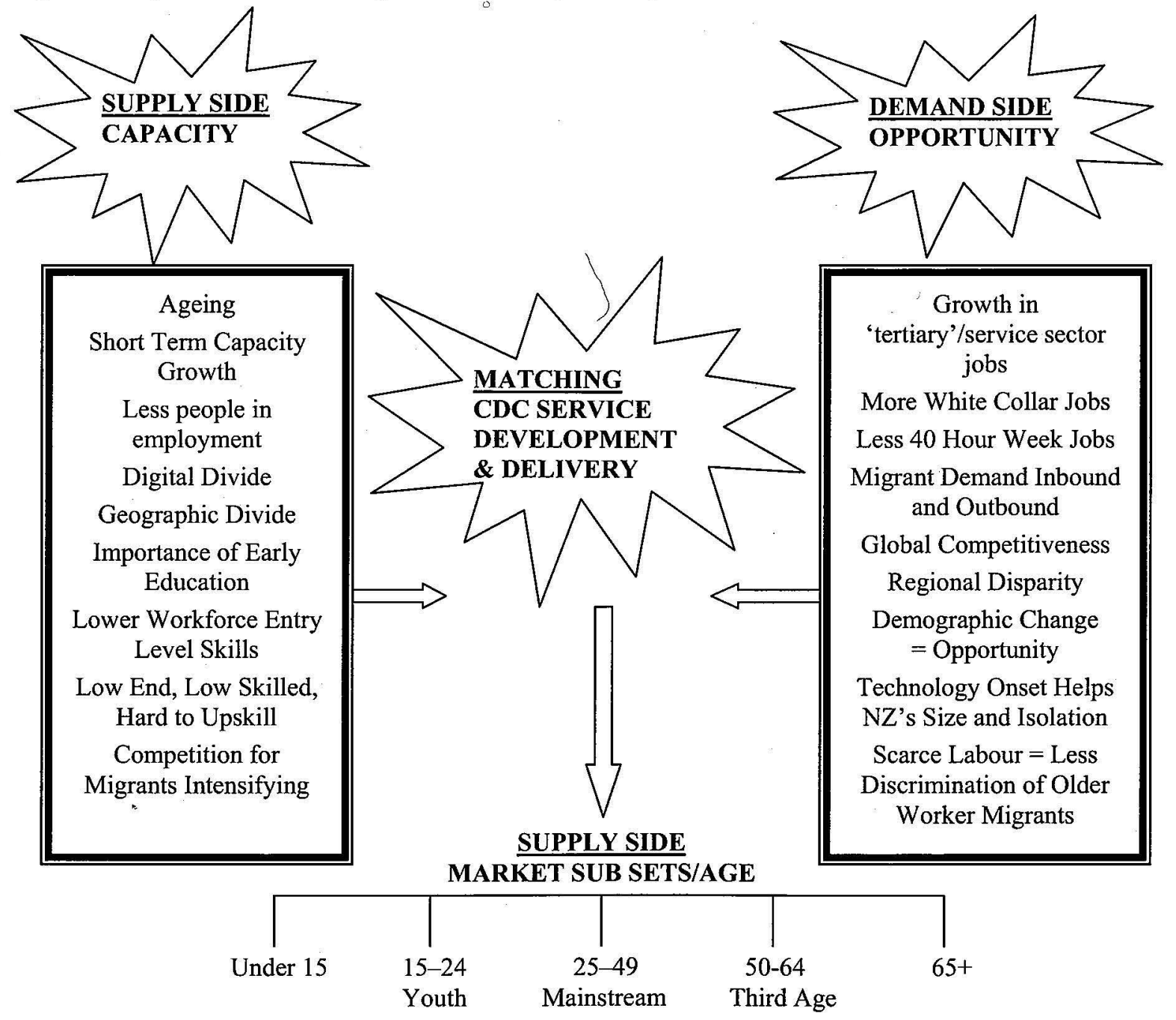

\section{Research uses of the HCF}

The Massey University Regional Labour Market Dynamics and Economic Participation programme's use of the framework has already been cited. The chief focus of Bartley et al.'s paper at LEW 9 was on the mediating role played by education and training institutions as part of the matching process in regional labour markets.

The publication of that use was serendipitous and inspired a Massey and Lincoln team to use the framework as the framework for a research project being tendered at the time by the Ministry of Agriculture and Forestry's Sustainable Farming Fund.

In June 2000 a sample of farmers had identified the shortage of skilled labour as one of their major concerns (Wharton, 2001). Perceived labour shortages have been used in agriculture world wide to urge governments to provide more cheap compliant labour to ease producers labour problems and costs. This has been achieved by the following strategies: by encouraging immigration from areas of labour oversupply; by subsidised development of mechanisation of labour intensive processes; and by encouraging improving employment conditions and 
retaining existing staff. In New Zealand such shortages had been the subject of substantial debate at the time of the Agricultural Development Conference 1963-64; during the late 1970s and early 1980s when the initial kiwifruit boom was about to reach maturity and need harvesting; and most recently since the end of the twentieth century, a problem highlighted by the difficulties finding and keeping staff in dairy farming enterprises (Morriss et al., 2002).

The Ministry of Agriculture and Forestry went out to tender to investigate this problem just before LEW 9. Subsequent research resulted in a report Skill and Labour Requirement in the Primary Sector - People make the Difference (Morriss, Tipples, Townshend, Mackay and Eastwood, 2001), which is summarised here.

\section{Skill and Labour requirement in the Primary Sector (Morriss et al., 2001)}

The project specification allowed the researchers considerable scope in how they developed the research. Work was divided along the lines suggested by the Human Capability Framework. The Massey team undertook the study of all those factors helping to develop human capacity in the industry. The Lincoln team was to explore the opportunities available in the Primary Sector, which was defined as covering all of agriculture, horticulture and forestry. Matching was to be considered subsequently.

The Massey team set up a live internet website of all industry education and training courses, and their providers, to establish whether industry needs were being met. The Lincoln team worked along more traditional research lines with statistical and literature reviews, leading to a survey of primary producers, to determine whether they perceived there was a labour or skill shortage, and what they perceived their educational and training needs were.

\section{Results}

Information gathered from the Massey ifternet site showed there were 101 education and training providers, providing some 433 primary industry education and training programmes from Ph.Ds to basic skill enhancement. At the same time (over the 1990s) the numbers of Effective Full-time Students in all programmes (Degree, Sub-degree and Extramural) had all declined. The free market in education services has delivered more courses to smaller numbers of students, throwing into question the viability of many providers, including those with long established reputations. There did not appear to be any shortage of available education or training programmes, although some specific subject areas may not have been covered.

The random postal survey conducted from Lincoln generated 762 useable questionnaires out of 1773 possible, or a $43 \%$ response rate. This was considered to be very satisfactory. The resulting data showed:

1. Farmers had avoided the need to employ as many staff by the tactic of engaging contractors for a much larger amount of farm work. This trend appeared to have increased following the Employment Contracts Act 1991 and the debate about achieving greater flexibility in employment.

2. More than half of farmers surveyed (58\%) considered that there was a shortage of candidates for jobs advertised with the skills they considered important. However, when asked about their actual experiences of recruiting between 1 April 2000 and 31 March 2001, only 196 or 28 percent had done so, but some several times. In 124 cases they thought that the response was adequate $(53 \%)$, while in 109 cases they believed it was inadequate $(47 \%)$. Most often this was because there was a lack of adequately skilled, knowledgeable, experienced staff ( $30 \%$ of reasons cited for inadequate response). So it appears that slightly more primary sector employers believed there was a labour shortage than actually experienced it.

3. Nine reasons for a possible labour shortage were generated from employers. Respondents were asked to rate the importance of each on a 4-point scale from 'Unimportant' (1) to 'Very important' (4). Most important causes of the labour shortage were 'Poor treatment of staff by employers' (mean=2.24), 'Manual skills not being valued in the education system' (mean=2.24), and 'Overall image of the agricultural industry is not attractive to job seekers' (mean=2.23).

4. When farmers and others surveyed $(n=515)$ were recruiting they sought largely generic skills rather than specific industry related skills. The attributes most sought were 'Good work ethics and attitudes' (30\%),

'Honesty' (18\%), 'Willingness to learn and follow instructions' (10\%), 'Good communications, listening skills and compatible personality' (7\%) and 'Common sense and intelligence (5\%). 'Good skills and practical experience' were only sought in $14 \%$ of cases. Many producers believed they could instruct and train for the basic skills needed by their enterprises.

When the data from the two parts of the research were compared, marked discrepancies between what industry appears to want and what providers appear to provide became apparent. Within the Human Capability Framework, one of the roles of education and training is to facilitate the matching of capability with opportunity, which can be obtained by providers aligning the learning outcomes and aims of their programmes with the needs of employers. Using a rather crude word search of aims and learning outcomes given by most providers, a comparison was made with the skills and attributes most often cited by employers as what they were seeking in new recruits. The results are compared in Table 1.

Education and training programmes focussed mainly on meeting the skill and practical experience needs of 
has highlighted how enlightened employers are paying good wages for dairy staff, providing rostered time-off, and with early possibilities of management responsibilities. Paying dairy staff more can only improve the image of the industry. The cash nexus cannot be ignored.

\section{The reactions of academe}

The results of the research were presented at the 2002 AIRAANZ Conference Celebrating Excellence (Tipples and Morris, 2002) in the un-refereed stream. Subsequently, an editor of the New Zealand Journal of Industrial Relations asked if we would like to have the paper published in the NZJIR. However, the paper was rejected by the anonymous referees, with the following comment:

“...The paper gives considerable weight to the Human Capability Framework, which is a very simplistic model of the labour market. The table on matching recruitment qualifications to employer needs in the primary sector gives results that would almost certainly be repeated if a similar survey was directed at employers in most other industry sectors.

There is a certain superficiality with the treatment of this topic which does not sit comfortably inside a serious academic journal such as the NZJIR."

The editor commented that he recognised the importance of the topic for the country and that he endorsed further consideration of the topic which could be the subject of further submissions, but the paper had been rejected. It was not clear from the comments whether the referees were rejecting the HCF concept or just that particular treatment of it.

\section{Other research}

The Human Capability Framework has provided a useful framework for other research in the primary sector. It has been particularly useful in setting the context for Reuben Edkins study of the Amuri Dairy Employers Group (see Edkins and Tipples, 2002). The Amuri Dairy Employers Group has a legitimate claim to two employment 'firsts' first employment code of practice; and first use of an independent auditing of employment practices in the primary sector. Both were on the initiative of the Group and are discussed by Reuben in our paper.

Another proposed use of the concept is to apply it as a whole to the dairy industry and its future employment problems. An unsuccessful application was made to the Future of Work Research Fund of the Department of Labour to fund this project (Tipples and Verwoerd, 2002). Now other sources will have to be tapped.

\section{Future research}

The academic acceptability of the Human Capability Framework is still in doubt. Perhaps the referees of the NZJIR did not realise that it is a framework and were evaluating it as a model with precise definitions. The advantage of the HCF is that it can be varied according to the type of problem to which it is being applied. Relevance of related factors will clearly vary according to the context, but that is one of its strengths for both policy issues and practical problems of 'real world' research. The use of the concept in research which meets the criteria of serious academic journals is therefore desirable. In addition, the origins of the concept and, in particular, the intellectual strands from which it has evolved are still unclear. The role of the OECD on New Zealand's employment polices and the interactions between the Department of Labour and the OECD merit further study. Another strand which should be considered is the work of development economist/philosopher Amartya Sen (Sen, 1985 and 1999), who has written extensively of human capabilities, even in the same context as human capital (Sen ,1999, 292-297).

\section{References}

ADC (1996) The Agricultural Development Conference 1963-64. Government Printer: Wellington.

Bartley, Allen, Dupuis, Ann and de Bruin, Anne (2001) Regional Labour Market Dynamics and Economic Participation: The Mediation Role of Education and Training Institutions. Ninth Conference on Labour, Employment and Work in new Zealand. Institute of Geography., Victoria University of Wellington: 148-155.

Canterbury Development Corporation (2002) Workforce Capability and CDC. Unpublished typescript.

Department of Labour (1998) Corporate Plan 19981999. Wellington.

Department of Labour (1999a) Report of the Department of Labour for the year ended 30 June 1999. Wellington.

Department of Labour (1999b) Corporate Plan 19992000. Wellington.

Department of Labour (1999c) Human Capability: a framework for analysis. Wellington.

Department of Labour (1999d) Briefing to Incoming Ministers. Wellington.

Department of Labour (2000a) Report of the Department of Labour for the year ended 30 June 2000. Wellington 
Department of Labour (2000b) Strategic Directions 2000-01. Wellington.

Department of Labour (2001a) Workforce 2010. Wellington.

Department of Labour (2001b) Report of the Department of Labour for the year ended 30 June 2000. Wellington

Department of Labour (2001c) Strategic Directions 2001-02. Wellington.

Edkins, Reuben and Tipples, Rupert (2002) Dairying and Employment in the Amuri: 1983-2002. Proceedings of the $10^{\text {th }}$ Labour, Employment and Work Conference, Victoria University of Wellington.

Morriss, Stuart; Tipples, Rupert; Townshend, Wendy; McKay, Bruce and Eastwood, Callum (2001) Skill and Labour Requirement in the Primary Sector - "People make the Difference". Report prepared for the Ministry of Agriculture and Forestry (RA 30/2000). Massey and Lincoln Universities. Available at: http://www.maf.govt.nz/sff/media/human-resources-inagriculture/others/index.htm

OECD (2001) The Well-being of Nations - The Role of Human and Social Capital. Paris.

Sen, Amartya (1985) Commodities and Capabilities. Deventer: North Holland.

Sen, Amartya (1999) Development as Freedom. Oxford: O.U.P.

Tipples, Rupert and Morriss, Stuart. (2002) The farm labour crisis A problem for the new millennium? Proceedings of the $16^{\text {th }}$ AIRAANZ Conference, Celebrating Excellence, 257-266, Queenstown.

Tipples, Rupert and Verwoerd, Nona (2002) Future dairy farm employment problems - An application to the Future of Work Research Fund, Department of Labour.

Wharton, Tony (2001) Identifying the Sectors' Concerns, Proceedings of the New Zealand Agricultural and Resource Economics Conference, Blenheim, July. 